\title{
Inhibition of Human Liver Cytochrome P450 by Star Fruit Juice
}

\author{
Jiang-Wei Zhang ${ }^{1,2}$, Yong Liu', Jie Cheng ${ }^{1,2}$, Wei Li ${ }^{1,2}$, Hong Ma ${ }^{1}$, Hong-Tao Liu', ${ }^{1,2}$, Jie Sun ${ }^{3}$, Li-Ming \\ Wang $^{3}$, Yu-Qi He ${ }^{4}$, Yun Wang ${ }^{4}$, Zheng-Tao Wang ${ }^{4}$, Ling Yang ${ }^{1, *}$
}

\begin{abstract}
${ }^{1}$ Laboratory of Pharmaceutical Resource Discovery, Dalian Institute of Chemical Physics, Chinese Academy of Sciences, Zhongshan Road, Dalian, China ${ }^{2}$ Graduate School of Chinese Academy of Sciences, Beijing, China ${ }^{3}$ The Second Affiliated Hospital of Dalian Medical University, Dalian, China ${ }^{4}$ University of Traditional Chinese Medicine, Shanghai, China
\end{abstract}

Received, December 15, 2006; Revised, October 8, 2007; Accepted, October 9, 2007, Published October 10, 2007.

\begin{abstract}
Purpose. To examine the inhibitory effects of star fruit (Averrhoa carambola) juice towards seven major cytochrome P450 (CYP) isoforms and NADPH-cytochrome $\mathrm{P} 450$ reductase (CPR). Methods. The inhibitory effects of star fruit juice $(0.5$ to $5 \%, \mathrm{v} / \mathrm{v})$ against the activities of seven CYP isoforms including CYP1A2, CYP2A6, CYP2C8, CYP2C9, CYP2D6, CYP2E1, CYP3A4 and CPR were examined in human liver microsomes. To identify time-dependent inhibition, star fruit juice $(2.5 \%, \mathrm{v} / \mathrm{v})$ was preincubated with microsomes and a NADPH-generating system for 0-15 min, and then the extent of inhibition towards seven CYP isoforms were examined. Results. Star fruit juice $(5.0 \%, \mathrm{v} / \mathrm{v})$ was found to inhibit all the activities of CYP isoforms tested by more than $70 \%$. Based on the half inhibition values $(\%, v / v)$, the inhibitory effects towards different CYP isoforms were in the following order: CYP2A6 (0.9) > CYP1A2 (1.4) > CYP2D6 (1.6) > CYP2E1 (2.0) > CYP2C8 (2.2) > CYP2C9 (3.0) > CYP3A4 (3.2). Time-dependent inhibition was not observed towards any of the tested CYP isoforms. In addition, star fruit juice was found not to inhibit the activity of CPR. Conclusions. Star fruit juice inhibited the seven CYP isoforms tested, with the strongest inhibitory effect against CYP2A6 and the least towards CYP3A4.
\end{abstract}

\section{INTRODUCTION}

Fruit juice-drug interactions (FDIs) have been a concern since the discovery of the grapefruit juice -drug interaction and much attention has been paid to the inhibitory effects of all kinds of fruit juice towards cytochrome P450 (CYP) (1-5). Besides grapefruit juice, juice from other fruits such as banpeiyu (1), pomegranate (2), star fruit $(3,4)$, black berry, and wild grape (5) were also found to inhibit CYP3A in vitro.

Amongst the fruit juices mentioned, star fruit (Averrhoa carambola) juice was found to be the most potent inhibitor of CYP3A. Star fruit juice $(5.0 \%, \mathrm{v} / \mathrm{v})$ inhibited midazolam 1'-hydroxylation almost completely (3). In vivo evidence also suggested that star fruit juice inhibited the activity of CYP3A in rats (4). Compared to the control, the area under the concentration-time curve of carbamazepine (a typical CYP3A substrate) increased 1.3-fold following $2 \mathrm{~mL}$ star fruit juice administration (4). This indicated that FDI could occur in humans when star fruit juice is co-administered with drugs containing CYP3A substrates.

Star fruit juice was found to inhibit phenobarbital metabolism in rats (6), and phenobarbital was considered to be a substrate of CYP2C (7). This indicated that inhibition of CYPs by star fruit might not be limited to CYP3A. However, there was little information concerning star fruit juice's inhibitory effects of human CYP isoforms other than CYP3A4. Although CYP3A4 is the dominant CYP isoform, other CYP isoforms that are responsible for drug clearance account for a considerable amount of total CYP content in both liver and intestine $(8,9)$. Thus it is important to examine the inhibitory effect of star fruit juice towards major CYP isoforms besides CYP3A4. Moreover, NADPH-cytochrome P450 reductase (CPR), which facilitates efficient CYP activity, plays an important role in the process of electron transfer from NADPH to CYP (10). Therefore, it is also necessary to investigate whether star fruit juice inhibits such activity.

In this study, the FDIs potential of star fruit juice was investigated by examining its inhibitory effects towards CPR and seven major CYP isoforms, including CYP1A2, CYP2A6, CYP2C8, CYP2C9, CYP2D6, CYP2E1, and CYP3A4 in human liver microsomes (HLMs).

Corresponding Author: Dr. Ling Yang, Laboratory of Pharmaceutical Resource Discovery, Dalian Institute of Chemical Physics, Chinese Academy of Sciences, Dalian, China, e-mail: yling@dicp.ac.cn 


\section{MATERIALS AND METHODS}

\section{Chemicals.}

D-glucose-6-phosphate, glucose-6-phosphate dehydrogenase, $\mathrm{NADP}^{+}, \quad$ corticosterone, phenacetin, acetaminophen, 4'-hydroxydiclofenac, chlorzoxazone, paclitaxel, MTT-formazan, 7-hydroxycoumarin, 6-hydroxychlorzoxazone, MTT, and 6 $\beta$-hydroxytestosterone were purchased from Sigma-Aldrich (St. Louis, MO, USA). Testosterone was obtained from Acros Organics (Morris Plains, NJ, USA). Coumarin, diclofenac, and dextromethorphan were obtained from ICN Biomedicals, Inc. (Aurora, Ohio, USA) and $6 \alpha$-hydroxypaclitaxel was purchased from BD Biosciences (Woburn, MA, USA). All other reagents were of HPLC grade or of the highest grade commercially available.

\section{Human Liver Microsomes.}

Human livers were obtained from three Chinese autopsy samples (male, ages 27, 29, and 42, respectively) from Dalian Medical University, with the approval of the university's ethics committee. The medication history of the donors was not known. Liver specimens were stored in liquid nitrogen until preparation of microsomes. Microsomes from three livers were prepared individually using differential ultracentrifugation as described previously (11). Protein concentrations of microsomes were determined by the Lowry method using bovine serum albumin as standards (12). Total CYP concentration was in the range of $0.16-0.35$ $\mathrm{nmol} / \mathrm{mg}$ protein determined according to Omura and Sato (13) with the use of a molar extinction coefficient of 91,000. Equal amounts of CYP from each of the liver sample were then pooled and the pooled HLMs were diluted to $10 \mathrm{mg} / \mathrm{mL}$ and stored at $-80^{\circ} \mathrm{C}$.

\section{Star Fruit Juice Samples.}

Fresh star fruits from Taiwan or Thailand, were obtained from local supermarkets. The edible part of the fruit was placed in a juicer immediately after purchase and the extracted juice was filtered through a $0.45-\mu \mathrm{m}$ membrane. Fresh juice samples were stored at $-30{ }^{\circ} \mathrm{C}$ and thawed in ice-cold water before use. The inhibition studies were completed within one month of juice preparation.

\section{Determination of Total Phenolic and Total Flavonoid Content in Star Fruit Juice.}

The total phenolic content was determined according to the method of Shui et al (14) with slight modification. Gallic acid standard solution $(2.0 \mathrm{mg} / \mathrm{mL})$ was prepared by dissolving $0.100 \mathrm{~g}$, accurately weighed, in $50 \mathrm{~mL}$ of distilled water. The solution was then diluted to working standard solutions in concentrations of $0.1,0.2,0.3,0.4$, 0.5 and $0.6 \mathrm{mg} / \mathrm{mL}$. A volume of $20 \mu \mathrm{L}$ of star fruit juice or gallic acid standard was mixed with $0.9 \mathrm{~mL}$ of Folin-Ciocalteu reagent (previously diluted 10-fold with distilled water). The mixture was allowed to stand at room temperature for 5 $\mathrm{min}$, and then $0.6 \mathrm{~mL}$ of sodium bicarbonate $(7.5 \%)$ was added. After standing for $10 \mathrm{~min}$ at 50 ${ }^{\circ} \mathrm{C}$, the mixture was diluted to a total volume of 3 $\mathrm{mL}$ with distilled water. The absorbance at 765 $\mathrm{nm}$ was measured and results were expressed as $\mathrm{mg} / \mathrm{mL}$ gallic acid equivalents.

Total flavonoid content was determined by a colorimetric method described previously (15). Quercetin standard solution $(1.0 \mathrm{mg} / \mathrm{mL})$ was prepared by dissolving $0.100 \mathrm{~g}$, accurately weighed, in $100 \mathrm{~mL}$ of methanol. Fifty microliters of star fruit juice or quercetin standard solution $(0$, $50,100,150,200,250,300 \mu \mathrm{L}$ ) was mixed with $150 \mu \mathrm{L}$ of a $5 \% \mathrm{NaNO}_{2}$ solution. After 6 min, 150 $\mu \mathrm{L}$ of a $10 \% \mathrm{AlCl}_{3} \cdot 6 \mathrm{H}_{2} \mathrm{O}$ solution was added, and the mixture was allowed to stand for a further 5 min. After adding $0.5 \mathrm{~mL}$ of $1 \mathrm{M} \mathrm{NaOH}$, the total volume was then brought up to $2.3 \mathrm{~mL}$ with distilled water. The solution was well mixed, and the absorbance was measured immediately against the prepared blank at $510 \mathrm{~nm}$. The results were expressed as $\mathrm{mg} / \mathrm{mL}$ quercetin equivalents.

\section{Assays of CYP Isoforms.}

Assays of the CYP isoforms were based on the following probe reactions: phenacetin O-deethylation(CYP1A2), coumarin 7 - hydro xylation (CYP2A6), paclitaxel 6 $\alpha$-hydroxylation (CYP2C8), diclofenac 4'-hydro-xylation (CYP2C9), dextromethorphan O-demethylation (CYP2D6), chlorzoxazone 6-hydroxylation (CYP2E1), and testosterone 6 $\beta$-hydroxylation (CYP3A4) $(16,17)$. To characterize the pooled HLMs, marker reactions of seven CYP isoforms were examined, and apparent $\mathrm{K}_{\mathrm{m}}$ values were estimated (Table 1). Assay methods including incubation and analytical conditions are listed in Tables 1 and 2, respectively. The incubation mixture $(200 \mu \mathrm{L})$ included $100 \mathrm{mM}$ potassium phosphate buffer ( $\mathrm{pH}$ 7.4), NADPH-generating system $\quad(1.0 \quad \mathrm{mM} \quad \mathrm{NADP}+, \quad 10 \mathrm{mM}$ D-glucose-6-phosphate, $\quad 1.0 \quad$ unit $/ \mathrm{mL}$ of glucose-6-phosphate dehydrogenase, and $4.0 \mathrm{mM}$ $\mathrm{MgCl}_{2}$ ), HLMs, and individual probe substrate. All experiments were performed within the linear range of incubation time and protein concentration. 
Dextromethorphan was dissolved in water, and other substrates were dissolved in methanol with a final concentration of $0.5 \%(\mathrm{v} / \mathrm{v})$. After 3-min preincubation at $37{ }^{\circ} \mathrm{C}$, the reaction was initiated by addition of the NADPH-generating system. After the defined incubation time, the reaction was then terminated by adding $100 \mu \mathrm{L}$ acetonitrile $(10 \%$ trichloroacetic acid for CYP2A6) together with internal standard. The reaction mixture was kept on ice until it was centrifuged at $20,000 \times \mathrm{g}$ for $10 \mathrm{~min}$ at $4{ }^{\circ} \mathrm{C}$. Aliquots of the supernatants were analyzed by HPLC (Table 2).

\section{Inhibition of CYP Isoform Activities by Star Fruit Juice.}

The inhibition study was conducted by adding star fruit juice $(0.5 \%$ to $5.0 \%, \mathrm{v} / \mathrm{v})$ to the reaction mixture before the addition of the NADPH-generating system. The incubation was carried out as described above. The inhibitory effect on the CYP activity was expressed as the percentage of the control activity in the absence of star fruit juice.

To examine whether star fruit juice inhibited the activity of CYPs in a time-dependent manner, star fruit juice $(2.5 \%, \mathrm{v} / \mathrm{v})$ was preincubated with HLMs, the NADPH-generating system, and buffer for $0,5,10$, or $15 \mathrm{~min}$ at $37{ }^{\circ} \mathrm{C}$. The reaction was initiated by addition of substrates.

\section{Assay of CPR.}

The activity of CPR was based on its ability to reduce3-(4,5-dimethylthiazol-2-yl)-2, 5 - diphen - yltetrazoli um bromide (MTT) to MTT-formazan in the presence of the NADPH-generating system (18). The assay of CPR was performed according to the method of Yim et al. (18) with slight modification. The reaction mixtures, with total volumes of $0.5 \mathrm{~mL}$, consisted of $100 \mathrm{mM}$ potassium phosphate buffer ( $\mathrm{pH}$ 7.4), the NADPH-generating system $\left(0.5 \mathrm{mM} \mathrm{NADP}{ }^{+}, 5.0\right.$ $\mathrm{mM}$ D-glucose-6-phosphate, 0.5 unit $/ \mathrm{mL}$ of glucose-6-phosphate dehydrogenase, and $4.0 \mathrm{mM}$ $\left.\mathrm{MgCl}_{2}\right), 0.5 \mathrm{mg} / \mathrm{mL}$ HLMs and $200 \mu \mathrm{M}$ MTT. The reference cuvette contained reaction mixture without MTT. The amount of MTT-formazan was determined from a calibration curve (4.77, 9.54, $18.08,28.62, \quad 38.16 \mathrm{nmol})$. After 5-min preincubation at $37{ }^{\circ} \mathrm{C}$, the reaction was initiated by the addition of MTT. Absorbance at $610 \mathrm{~nm}$ $\left(\mathrm{A}_{610}\right)$ was monitored continuously for 30 seconds (18) in a Jasco V-530 spectrophotometer (Tokyo, Japan) using a double beam model. The slopes of $\mathrm{A}_{610}$-time plots in the first 30 seconds were used to calculate the formation rates of MTT-formazan.

Inhibition of CPR Activity by Star Fruit Juice. The inhibition study was conducted by adding star fruit juice $(1.0 \%$ to $5.0 \%, \mathrm{v} / \mathrm{v})$ to the incubation mixture of CPR before the addition of MTT. The assay was conducted as described above. The inhibitory effects on the CPR activity were expressed as the percentage of the control activity in the absence of star fruit juice. All incubations were carried out in duplicate unless otherwise stated and the average of duplicate determinations was presented in the results, with standard deviations generally below $10 \%$.

Table 1. Isoforms tested, marker reactions, $K_{m}$, and incubation conditions used in the inhibition study

\begin{tabular}{|c|c|c|c|c|c|}
\hline CYPs & Maker reactions & $\begin{array}{l}\text { Estimated } K_{m} \\
(\mu M)\end{array}$ & $\begin{array}{l}\text { Substrate } \\
\text { concentration } \\
(\mu \mathrm{M})\end{array}$ & $\begin{array}{l}\text { Protein } \\
\text { concentration } \\
(\mathbf{m g} / \mathbf{m l})\end{array}$ & $\begin{array}{l}\text { Incubation } \\
\text { time } \\
(\mathrm{min})\end{array}$ \\
\hline $1 \mathrm{~A} 2$ & $\begin{array}{l}\text { Phenacetin } \\
\text { O-deethylation }\end{array}$ & 44 & 40 & 0.2 & 30 \\
\hline $2 \mathrm{~A} 6$ & $\begin{array}{l}\text { Coumarin } \\
\text { 7-hydroxylation }\end{array}$ & 1.0 & 1.0 & 0.1 & 10 \\
\hline $2 \mathrm{C} 8$ & $\begin{array}{l}\text { Paclitaxel } \\
6 \alpha \text {-hydroxylation }\end{array}$ & 13 & 10 & 0.5 & 30 \\
\hline $2 \mathrm{C} 9$ & $\begin{array}{l}\text { Diclofenac } \\
\text { 4'-hydroxylation }\end{array}$ & 14 & 10 & 0.3 & 10 \\
\hline 2D6 & $\begin{array}{l}\text { Dextromethorphan } \\
\text { O-demethylation }\end{array}$ & 4.8 & 25 & 0.25 & 20 \\
\hline $2 \mathrm{E} 1$ & $\begin{array}{l}\text { Chlorzoxazone } \\
\text { 6-hydroxylation }\end{array}$ & 130 & 120 & 0.4 & 30 \\
\hline $3 \mathrm{~A} 4$ & $\begin{array}{l}\text { Testosterone } \\
\text { 63-hydroxylation }\end{array}$ & 49 & 50 & 0.5 & 10 \\
\hline
\end{tabular}


Table 2. HPLC conditions for the relevant P450 isoforms.

\begin{tabular}{|c|c|c|c|}
\hline CYPs & $\begin{array}{l}\text { Internal standard } \\
\text { (Concentration, } \mu \mathrm{M})\end{array}$ & Mobile phase and gradient & Detection \\
\hline $1 \mathrm{~A} 2$ & 7-Hydroxycoumarin $(30 \mu \mathrm{M})$ & $\begin{array}{l}\text { Methanol: Phosphate buffer }(\mathrm{pH}=3.0,50 \mathrm{mM})= \\
34: 66\end{array}$ & UV $245 \mathrm{~nm}$ \\
\hline $2 \mathrm{~A} 6$ & - & Acetonitrile: Acetic acid $(0.1 \%, \mathrm{v} / \mathrm{v})=35: 65$ & $\begin{array}{l}\text { Fluo Ex/Em: } \\
340 \mathrm{~nm} / 456 \mathrm{~nm}\end{array}$ \\
\hline $2 \mathrm{C} 8$ & - & Methanol: Water $=65: 35$ & UV $230 \mathrm{~nm}$ \\
\hline $2 \mathrm{C} 9$ & Coumarin $(60 \mu \mathrm{M})$ & $\begin{array}{l}\text { Acetonitrile (A): Phosphate buffer }(\mathrm{pH}=7.4 \text {, } \\
100 \mathrm{mM}, \mathrm{B})=32: 68,0-9 \mathrm{~min}, 68 \% \mathrm{~B}-32 \% \mathrm{~B}\end{array}$ & UV $280 \mathrm{~nm}$ \\
\hline 2D6 & - & $\begin{array}{l}\text { Acetonitrile: Phosphate buffer } \quad(\mathrm{pH}=3.0,50 \\
\mathrm{mM})=25: 75\end{array}$ & $\begin{array}{l}\text { Fluo Ex/Em: } 235 \\
\mathrm{~nm} / 310 \mathrm{~nm}\end{array}$ \\
\hline $2 \mathrm{E} 1$ & Phenacetin $(300 \mu \mathrm{M})$ & $\begin{array}{l}\text { Acetonitrile: Acetic acid }(0.5 \%, \mathrm{v} / \mathrm{v})=22: 78 \text {, } \\
1-10 \mathrm{~min}, 78 \% \mathrm{~B}-40 \% \mathrm{~B}\end{array}$ & UV $287 \mathrm{~nm}$ \\
\hline $3 \mathrm{~A} 4$ & Corticosterone $(20 \mu \mathrm{M})$ & $\begin{array}{l}\text { Methanol: Water }=52: 48,0-15 \mathrm{~min}, 48 \% \mathrm{~B}-30 \% \mathrm{~B} \text {; } \\
15-22 \mathrm{~min}, 30 \% \mathrm{~B}-20 \% \mathrm{~B}\end{array}$ & UV $254 \mathrm{~nm}$ \\
\hline
\end{tabular}

\section{RESULTS.}

To control the quality of juice samples, total phenolic and total flavonoid content were measured. As shown in Table 3, the total phenolic content was in the range of $0.60 \pm 0.02$ to $1.01 \pm$ $0.01 \mu \mathrm{g}$ gallic acid $\mathrm{mL}^{-1}$ fruit juice, and the total flavonoid content in the range of $2.37 \pm 0.05$ to $5.03 \pm 0.27 \mu \mathrm{g}$ quercetin $\mathrm{mL}^{-1}$ fruit juice. The star fruits used in the inhibition studies were the samples bought on May 01, 2006 unless otherwise stated.

In the present study, the inhibitory effects of star fruit juice were investigated in HLMs. The star fruit juice's inhibitory effects towards seven CYP isoforms, including CYP1A2, CYP2A6, CYP2D6, CYP2C8, CYP2C9, CYP2E1, and CYP3A4, are shown in Figure 1. At 5.0\% (v/v), star fruit juice showed different degrees of inhibition towards seven CYP isoforms. The values of half inhibition concentration $\left(\mathrm{IC}_{50}\right)$ were $1.4,0.9,2.2,3.0,1.6,2.0$, and $3.2 \%(\mathrm{v} / \mathrm{v})$ for CYP1A2, CYP2A6, CYP2C8, CYP2C9, CYP2D6, CYP2E1, and CYP3A4, respectively. Based on the $\mathrm{IC}_{50}$ values, star fruit juice's inhibition effects towards different CYP isoforms were found to be in the following order: CYP2A6 $>$ CYP1A2 > CYP2D6 > CYP2E1 > CYP2C8 > CYP2C9 > CYP3A4.

Star fruit juice inhibited CYP2A6 more potently than other isoforms tested. Subsequently further studies were performed to evaluate the inhibitory effects of star fruits obtained from different origin, purchase store, or purchase date. In spite of differences in origin, purchase store, or purchase time, juice made from the star fruits all inhibited CYP2A6 catalyzed coumarin 7-hydroxylation by more than $90 \%$ (Table 4 ).

Grapefruit juice is known to contain several mechanism-based inhibitors and grapefruit juice's inhibition has been characterized in a time-dependent nature (19). To examine whether star fruit juice inhibited the activity of CYPs in a similar way, the effect of preincubation time on the extent of inhibition was also studied. As shown in Figure 2, the extent of inhibition by star fruit juice $(2.5 \%, \mathrm{v} / \mathrm{v})$ towards CYP1A2, CYP2A6, CYP2C8, CYP2C9, CYP2D6, CYP2E1, and CYP3A4 were not altered significantly during the of preincubation period $(0-15 \mathrm{~min})$, suggesting that star fruit juice did not inhibit the tested isoforms in a time-dependent manner.

Because CPR played an important role in CYP-mediated reactions (10), it is possible that the non-selective inhibition of CYPs by star fruit juice could contribute to its inhibition of the CPR. To test this hypothesis, the inhibitory effect of star fruit juice towards CPR was evaluated. However, no inhibitory effect towards CPR was observed, as shown in Figure 3. 
Table 3. Total phenolics and flavonoids in star fruit juice samples. Mean $\pm \mathrm{SD}$ of quadruplicate determinations

\begin{tabular}{ccccc} 
Purchase date & Store & Origin & $\begin{array}{c}\text { Total } \\
\text { phenolics }^{\mathbf{a}}\end{array}$ & $\begin{array}{c}\text { Total } \\
\text { flavonoids }^{\mathbf{b}}\end{array}$ \\
\hline May 01, 2006 & New-mart1 & Taiwan & $0.60 \pm 0.02$ & $2.37 \pm 0.05$ \\
May 09, 2006 & Carrefour & Thailand & $1.01 \pm 0.01$ & $5.03 \pm 0.27$ \\
May 21, 2006 & New-mart2 & Taiwan & $0.86 \pm 0.02$ & $4.33 \pm 0.26$ \\
May 22, 2006 & New-mart1 & Taiwan & $0.71 \pm 0.02$ & $2.85 \pm 0.12$ \\
\hline \multicolumn{2}{c}{${ }^{\mathrm{a}} \mathrm{mg} \mathrm{gallic}^{-1}$ acid $\mathrm{ml}^{-1}$ fruit juice; ${ }^{\mathrm{b}} \mathrm{mg}$ quercetin $\mathrm{ml}^{-1}$ fruit juice }
\end{tabular}

Table 4. Reproducibility of coumarin 7-hydroxylation (CYP2A6) inhibition by star fruit juice $(5.0 \%, \mathrm{v} / \mathrm{v})$. Mean \pm SD of triplicate incubations.

\begin{tabular}{|c|c|c|c|}
\hline $\begin{array}{c}\text { Purchase } \\
\text { date }\end{array}$ & Store & Origin & $\begin{array}{c}\text { Residual } \\
\text { Activity (\%) }\end{array}$ \\
\hline $\begin{array}{l}\text { May 01, } \\
2006\end{array}$ & New-mart1 & Taiwan & $5.6 \pm 0.6$ \\
\hline $\begin{array}{c}\text { May 09, } \\
2006\end{array}$ & Carrefour & Thailand & $6.7 \pm 0.3$ \\
\hline $\begin{array}{l}\text { May 21, } \\
2006\end{array}$ & New-mart2 & Taiwan & $7.0 \pm 0.2$ \\
\hline $\begin{array}{c}\text { May 22, } \\
2006\end{array}$ & New-mart1 & Taiwan & $7.5 \pm 0.2$ \\
\hline
\end{tabular}

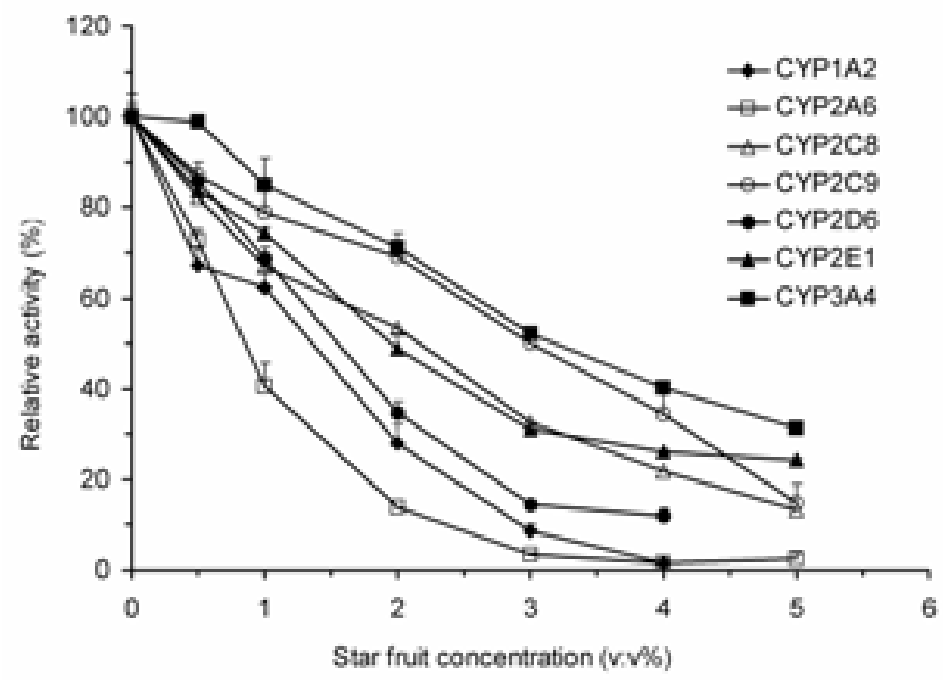

Figure 1. Inhibition of CYP isoforms by star fruit juice $(0.5$, $1.0,2.0,3.0,4.0,5.0 \%, \mathrm{v} / \mathrm{v})$ in human liver microsomes. Mean of duplicate incubations.

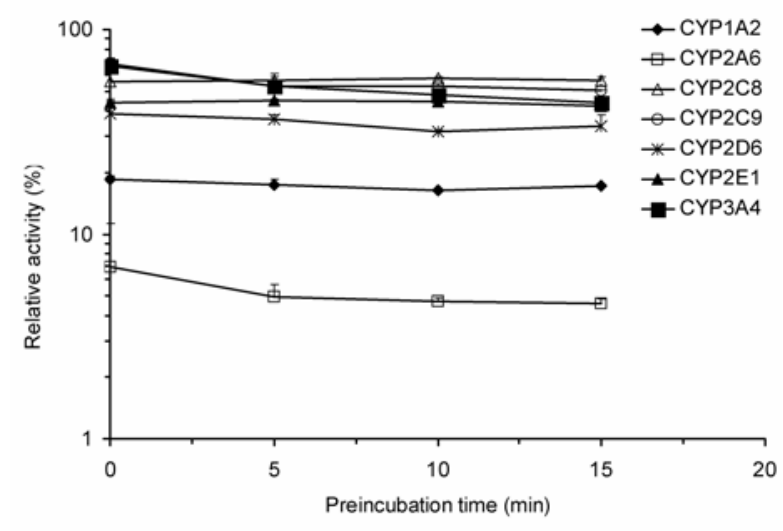

Figure 2. The effect of preincubation time $(0,5,10$, $15 \mathrm{~min}$ ) on the inhibition potencies of CYP isoforms by star fruit juice $(2.5 \%, \mathrm{v} / \mathrm{v})$. Mean of duplicate incubations.

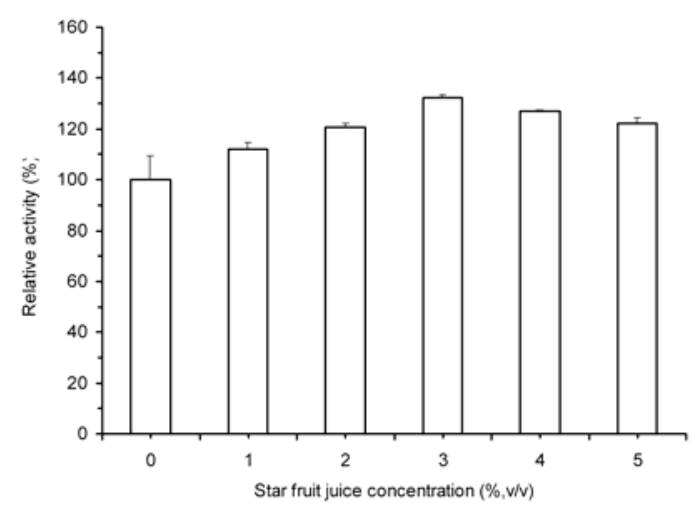

Figure 3. Effects of star fruit juice (1.0, 2.0, 3.0, 4.0, $5.0 \%, \mathrm{v} / \mathrm{v})$ on the activity of $\mathrm{CPR}$ in human liver microsomes. Mean of duplicate incubations. 


\section{DISCUSSION}

Fruits, the main sources of antioxidant in our diet, are beneficial in preventing age-related diseases, cancers, obesity, and heart disease (20). Fruits are consumed everyday, thus FDIs might be daily occurrences. Star fruit, largely planted in Southeast Asia and Brazil, is a popular fruit around the world (14). It is recommended in folk medicine as a diuretic, expectorant, and cough suppressant (21-23). For Brazilians, it is common to drink 300 to $500 \mathrm{~mL}$ of star fruit juice in a single day $(24,25)$. Therefore, the probability of star fruit-drug interactions is high if star fruit juice inhibits CYPs.

Our findings that star fruit juice inhibits CYP2C9 are in agreement with the observed star fruit juice-phenobarbital interactions in rats (6). Phenobarbital-induced sleeping time was prolonged by star fruit juice in a dose-dependent manner (6). Phenobarbital metabolism was dependent on genetic polymorphism of CYP2C (7). Valproic acid, an inhibitor of CYP2C9 (26), inhibits phenobarbital metabolism in both human and rat $(27,28)$. All these findings suggest that CYP2C was involved in phenobarbital metabolism. It is reasonable that star fruit juice inhibits phenobarbital metabolism by inhibiting CYP2C.

CYP2A6 is recognized as being involved in the activation of promutagens in tobacco (29). CYP2A6 inhibitors, such as 8-methoxypsoralen could suppress tumorigenesis induced by nicotine-related chemicals $(30,31)$. In the present study, star fruit juice was found to be a potent inhibitor of CYP2A6. Therefore, one might speculate that star fruit juice could be used as a chemopreventive agent against nicotine-related cancer. However, this assumption is not supported by our study since the selective inhibition against CYP2A6 needs to be verified in vivo.

Previous studies have suggested that star fruit juice, similar to grapefruit juice, might contain some compounds that are CYP inhibitors $(3,4,6)$. These compounds have not yet been identified. Some phenolics or flavonoids, such as gallic acid, catechin, (-)-epicatechin, proanthocyanidins, or their corresponding polymers were found in star fruit (20). It is possible that the inhibitory effect of star fruit juice is due to the presence of phenolics or flavonoids because certain phenolics (32) and flavonoids (33) are known to be CYP inhibitors. We therefore monitored the content of total phenolics and total flavonoids in the juice samples as comparators. However, further investigation is required to clarify the inhibitory components against CYP in star fruit.

Several other CYP isoforms such as CYP2C19 and CYP2B6 were not included in the present study. It is not known whether these isoforms could be inhibited by star fruit juice. In conclusion, the following summarizes the findings from this study.

1) Star fruit juice inhibits not only CYP3A4, but also CYP1A2, CYP2A6, CYP2C8, CYP2C9, CYP2D6, and CYP2E1,

2) The inhibitory effects of star fruit juice towards the CYP isoforms tested are not time-dependent and

3) Star fruit juice does not inhibit CPR. Since the inhibitory effect in vitro does not necessarily represent that which may occur in vivo, further research is necessary to investigate whether clinical relevant star fruit juice-drug interactions will occur in vivo.

\section{ACKNOWLEDGEMENT}

This work was supported by the 973 Program (2003CB716005) of the Ministry of Science and Technology of China, the National Natural Science Foundation of China (30640066) and (30630075).

\section{REFERENCES}

[1]. Fujita K, Hidaka M, Takamura N, Yamasaki K, Iwakiri T, Okumura M, Kodama H, Yamaguchi M, Ikenoue T, Arimori K. Inhibitory effects of citrus fruits on cytochrome P450 3A (CYP3A) activity in humans. Biol Pharm Bull, 26(9):1371-1373, 2003.

[2]. Hidaka M, Okumura M, Fujita K, Ogikubo T, Yamasaki K, Iwakiri T, Setoguchi N, Arimori $\mathrm{K}$. Effects of pomegranate juice on human cytochrome p450 3A (CYP3A) and carbamazepine pharmacokinetics in rats. Drug Metab Dispos, 33(5):644-648, 2005.

[3]. Hidaka M, Fujita K, Ogikubo T, Yamasaki K, Iwakiri T, Okumura M, Kodama H, Arimori K. Potent inhibition by star fruit of human cytochrome P450 3A (CYP3A) activity. Drug Metab Dispos, 32(6):581-583, 2004.

[4]. Hidaka M, Okumura M, Ogikubo T, Kai H, Fujita K, Iwakiri T, Yamasaki K, Setoguchi N, Matsunaga N, Arimori K. Transient inhibition of cyp3a in rats by star fruit juice. Drug Metab Dispos, 34(3):343-345, 2006.

[5]. Kim H, Yoon YJ, Shon JH, Cha IJ, Shin JG, Liu KH. Inhibitory effects of fruit juices on cyp3a activity. Drug Metab Dispos, 34(4):521-523, 2006.

[6]. Chen CL, Chou KJ, Wang JS, Yeh JH, Fang HC, Chung HM. Neurotoxic effects of carambola in rats: the role of oxalate. J Formos 
Med Assoc, 101(5):337-341, 2002.

[7]. Anderson GD. Pharmacogenetics and enzyme induction/inhibition properties of antiepileptic drugs. Neurology, 63(10 Suppl 4):S3-8, 2004.

[8]. Shimada T, Yamazaki H, Mimura M, Inui Y, Guengerich FP. Interindividual variations in human liver cytochrome P-450 enzymes involved in the oxidation of drugs, carcinogens and toxic chemicals: studies with liver microsomes of 30 Japanese and 30 Caucasians. J Pharmacol Exp Ther, 270(1):414-423, 1994.

[9]. Paine MF, Hart HL, Ludington SS, Haining RL, Rettie AE, Zeldin DC. The human intestinal cytochrome P450 "pie". Drug Metab Dispos, 34(5):880-886, 2006.

[10]. Sevrioukova IF, Peterson JA. NADPH-P-450 reductase: structural and functional comparisons of the eukaryotic and prokaryotic isoforms. Biochimie, 77(7-8):562-572, 1995.

[11]. Sanderink GJ, Bournique B, Stevens J, Petry M, Martinet M. Involvement of human CYP1A isoenzymes in the metabolism and drug interactions of riluzole in vitro. J Pharmacol Exp Ther, 282(3):1465-1472, 1997.

[12]. Lowry OH, Rosebrough NJ, Farr AL, Randall RJ. Protein measurement with the Folin phenol reagent. J Biol Chem, 193(1):265-275, 1951.

[13]. Omura T, Sato R. The Carbon Monoxide-Binding Pigment of Liver Microsomes. I. Evidence for Its Hemoprotein Nature. J Biol Chem, 239:2370-2385, 1964.

[14]. Shui GH, Leong LP. Residue from star fruit as valuable source for functional food ingredients and antioxidant nutraceuticals. Food Chemistry, 97(2):277-284, 2006.

[15]. Liu M, Li XQ, Weber C, Lee CY, Brown J, Liu RH. Antioxidant and antiproliferative activities of raspberries. J Agric Food Chem, 50(10):2926-2930, 2002.

[16]. Zhang JW, Liu Y, Li W, Hao DC, Yang L. Inhibitory effect of medroxyprogesterone acetate on human liver cytochrome P450 enzymes. Eur J Clin Pharmacol, 62(7):497-502, 2006.

[17]. Liu Y, Ma H, Zhang JW, Deng MC, Yang L. Influence of ginsenoside Rh1 and F1 on human cytochrome p450 enzymes. Planta Med, 72(2):126-131, 2006.

[18]. Yim SK, Yun CH, Ahn T, Jung HC, Pan JG. A continuous spectrophotometric assay for NADPH-cytochrome P450 reductase activity using

3-(4,5-dimethylthiazol-2-yl)-2,5-diphenyltetraz olium bromide. J Biochem Mol Biol, 38(3):366-369, 2005.

[19]. Guo LQ, Fukuda K, Ohta T, Yamazoe Y. Role of furanocoumarin derivatives on grapefruit juice-mediated inhibition of human CYP3A activity. Drug Metab Dispos, 28(7):766-771, 2000.

[20]. Shui G, Leong LP. Analysis of polyphenolic antioxidants in star fruit using liquid chromatography and mass spectrometry. J Chromatogr A, 1022(1-2):67-75, 2004.

[21]. Tsai MH, Chang WN, Lui CC, Chung KJ, Hsu KT, Huang CR, Lu CH, Chuang YC. Status epilepticus induced by star fruit intoxication in patients with chronic renal disease. Seizure, 14(7):521-525, 2005.

[22]. Carolino RO, Beleboni RO, Pizzo AB, Vecchio FD, Garcia-Cairasco N, Moyses-Neto M, Santos WF, Coutinho-Netto J. Convulsant activity and neurochemical alterations induced by a fraction obtained from fruit Averrhoa carambola (Oxalidaceae: Geraniales). Neurochem Int, 46(7):523-531, 2005.

[23]. Vasconcelos CM, Araujo MS, Silva BA, Conde-Garcia EA. Negative inotropic and chronotropic effects on the guinea pig atrium of extracts obtained from Averrhoa carambola L. leaves. Braz J Med Biol Res, 38(7):1113-1122, 2005.

[24]. Neto MM, da Costa JA, Garcia-Cairasco N, Netto JC, Nakagawa B, Dantas M. Intoxication by star fruit (Averrhoa carambola) in 32 uraemic patients: treatment and outcome. Nephrol Dial Transplant, 18(1):120-125, 2003.

[25]. Neto MM, Robl F, Netto JC. Intoxication by star fruit (Averrhoa carambola) in six dialysis patients? (Preliminary report). Nephrol Dial Transplant, 13(3):570-572, 1998.

[26]. Wen X, Wang JS, Kivisto KT, Neuvonen PJ, Backman JT. In vitro evaluation of valproic acid as an inhibitor of human cytochrome P450 isoforms: preferential inhibition of cytochrome P450 2C9 (CYP2C9). Br J Clin Pharmacol, 52(5):547-553, 2001.

[27]. Patel IH, Levy RH, Cutler RE. Phenobarbital--valporic acid interaction. Clin Pharmacol Ther, 27(4):515-521, 1980.

[28]. Anderson GD, Levy RH. The effect of valproate on the metabolism of phenobarbital in the rat. Pharm Res, 9(12):1622-1628, 1992.

[29]. Kamataki T, Fujieda M, Kiyotani K, Iwano S, Kunitoh H. Genetic polymorphism of CYP2A6 as one of the potential determinants of tobacco-related cancer risk. Biochem Biophys Res Commun, 338(1):306-310, 2005.

[30]. Takeuchi H, Saoo K, Yokohira M, Ikeda M, Maeta H, Miyazaki M, Yamazaki H, Kamataki T, Imaida K. Pretreatment with 8-methoxypsoralen, a potent human CYP2A6 inhibitor, strongly inhibits lung tumorigenesis induced 4-(methylnitrosamino)-1-(3-pyridyl)-1-butano ne in female $\mathrm{A} / \mathrm{J}$ mice. Cancer Res, 63(22):7581-7583, 2003.

[31]. Takeuchi H, Saoo K, Matsuda Y, Yokohira M, Yamakawa K, Zeng Y, Miyazaki M, Fujieda M, Kamataki T, Imaida K. Dose dependent inhibitory effects of dietary 8-methoxypsoralen on NNK-induced lung tumorigenesis in female A/J mice. Cancer Lett, 234(2):232-238, 2006.

[32]. Stupans L, Tan HW, Kirlich A, Tuck K, 
Hayball P, Murray M. Inhibition of CYP3A-mediated oxidation in human hepatic microsomes by the dietary derived complex phenol, gallic acid. J Pharm Pharmacol, 54(2):269-275, 2002.

[33]. Ho PC, Saville DJ, Wanwimolruk S. Inhibition of human CYP3A4 activity by grapefruit flavonoids, furanocoumarins and related compounds. J Pharm Pharm Sci, 4(3):217-227, 2001. 